\title{
Caracterização da qualidade fisiológica de sementes de arroz-crioulo da safra de 2010/2011
}

\section{Characterization of the physiological quality of landrace rice seed in the growing season of 2010/2011}

\author{
Cileide Maria Medeiros COELHO' ${ }^{\text {; }}$ Moisés M. POLLAK JÚNIOR ${ }^{2}$; Clovis Arruda SOUZA ${ }^{3}$; \\ Cirio PARIZOTO ${ }^{4}$
}

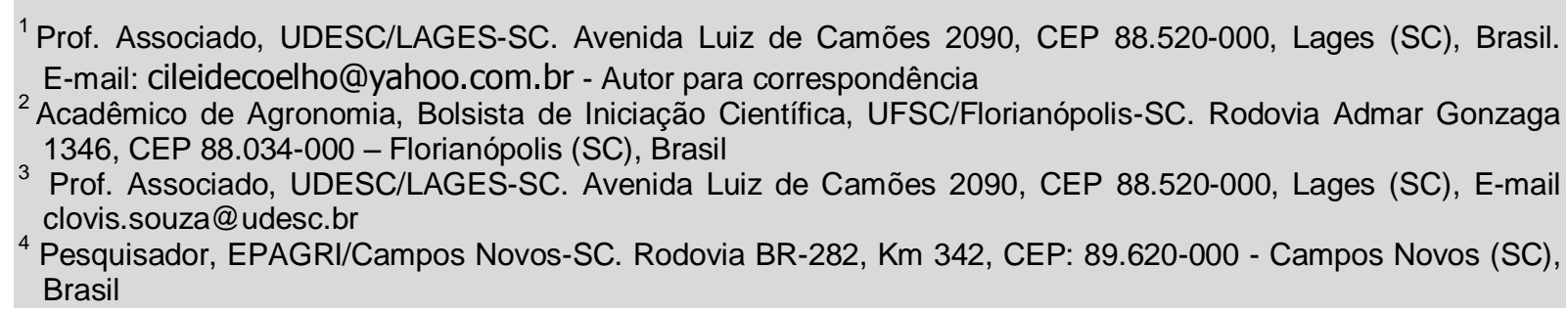

Recebido em: 12-09-2012; Aceito em: 23-05-2014

\begin{abstract}
Resumo
O cultivo de arroz de sequeiro, em Santa Catarina, tem diminuído substancialmente nos últimos anos, e as sementes são guardadas em domínio do próprio agricultor, o que compromete sua qualidade. Este trabalho tem o objetivo de resgatar os genótipos crioulos de arroz e caracterizar a qualidade fisiológica das sementes produzidas, indicando os genótipos mais promissores. $O$ experimento foi conduzido com onze cultivares crioulas de Oryza sativa: Amarelão, Agulha, Rosa 15, Mato Grosso, Gomes, Preto, Argentino, Kinsel, Camilo, Piriquitinho e Casca Roxa; todos referentes à safra de 2010/2011, produzidas em Campos Novos. As sementes foram avaliadas no laboratório da UFSC-CCA, quanto à viabilidade pelo percentual de germinação e vigor (tolerância ao estresse por envelhecimento acelerado, teste do frio e condutividade elétrica). Os testes de germinação e de vigor foram realizados com base nas Regras de Análises de Sementes, ambos com quatro repetições de 50 sementes. As médias foram comparadas pelo teste de Scott - Knott ao nível de $5 \%$ de probabilidade. Os resultados demonstraram a existência de variabilidade entre os genótipos para as caraterísticas fisiológicas das sementes. Das onze cultivares, as cultivares Agulha, Rosa 15 e Camilo apresentaram mais de $80 \%$ de germinação e maior tolerância ao estresse por envelhecimento acelerado e por frio, demonstrando elevado potencial fisiológico em suas sementes.
\end{abstract}

Palavras-chave adicionais: cultivares; germinação; Oryza sativa; vigor.

\begin{abstract}
The cultivation of upland rice in the state of Santa Catarina, Brazil, has decreased substantially in the recent years and the seeds are stored in the farmer's own field which compromises their quality. The objective of this work was to study landrace rice genotypes by characterizing their seeds physiological quality. The experiment was carried out with eleven cultivars: Amarelão, Agulha, Rosa 15, Mato Grosso, Gomes, Preto, Argentino, Kinsel, Camilo, Piriquitinho, and Casca Rosa the seeds of which were produced in the growing season of 2010/2011. The seeds were evaluated as to viability and vigor (accelerated aging, cold, and electrical conductivity tests). Each test was conducted with four 50 seed replications of each treatment. The results showed that the seeds of the cultivars Agulha, Rosa 15, and Camilo exhibited the highest tolerance to the aging and cold conditions and were, thus, considered the cultivars with the highest physiological potential.
\end{abstract}

Additional keywords: cultivars; germination; Oryza sativa; vigor.

\section{Introdução}

É visível a grande demanda atual para o uso do arroz de terras altas em plantio direto, principalmente de regiões favorecidas com boa distribuição da precipitação pluvial e/ou sob pivô central, com expectativas de altas produtivida- des, considerando a grande área usada atualmente com plantio direto de milho/soja, onde o arroz se apresenta como uma opção de rotação.

Em Santa Catarina, tem priorizado a realização de pesquisas em genética e manejo de arroz para o sistema irrigado, cultivado em terras baixas. Todavia, existe potencial econômico e condições de ambiente que comprovam 0 
desenvolvimento de cultivares de arroz adaptadas a terras altas, onde o cultivo é feito no sistema de sequeiro. As variedades de sequeiro em SC, em geral, têm sido cultivadas por famílias de agricultores tradicionais, especialmente do Oeste Catarinense. A produção do sequeiro no Estado tem sido com base no uso de sementes crioulas destinadas quase que exclusivamente para consumo próprio, ocupando uma área aproximada de 1.500 ha e produção de 3.000 t, na safra de 2009/2010 (SILVA, 2010).

O arroz de terras altas é cultivado em praticamente todo o Estado de Santa Catarina, havendo maior concentração nas microrregiões geográficas de São Miguel do Oeste, Chapecó, Xanxerê e Concórdia. Seu cultivo, a cada ano, vem perdendo espaço para a exploração de outras lavouras, principalmente o fumo, o milho e o feijão (CEPA, 2009).

É importante a avaliação do potencial de uso agrícola e nutricional das cultivares crioulas de arroz como forma de resgate deste recurso genético, como fonte de variabilidade para processo de melhoramento e como base para alimentação humana. Segundo Ribeiro et al. (2008), as cultivares crioulas constituem-se a base da sustentabilidade da agricultura familiar no Estado de Santa Catarina, e o reconhecimento desse potencial tem sido explorado na composição de populações de base genética estreita, destinadas à seleção de linhagens promissoras sob variações ambientais diversas.

Para auxiliar o agricultor nesta seleção e na manutenção deste recurso genético, existem pesquisadores que realizam a coleta e o armazenamento de sementes em bancos de germoplasmas. Este armazenamento garante apenas que tal recurso não seja perdido ao longo dos anos, mas não viabiliza o uso destes genótipos de forma sustentável. Para indicar os genótipos mais promissores, e que de fato sejam considerados cultivar crioula, é necessário conduzir estudos para diferenciá-las significativamente das cultivares comerciais, conforme a normativa da Lei de Sementes e Mudas 10.711/03 (Art. 2, inciso XVI) (BRASIL, 2003), que caracteriza sementes crioulas como aquela semente mantida pelo agricultor ao longo de anos, sendo mantida na propriedade na base de troca.

É necessária a correta identificação das cultivares por meio de suas características particulares para favorecer a multiplicação e o desenvolvimento de plântulas com bom estande inicial e ajudar a definir o potencial fisiológico das sementes destas cultivares. Assim, a qualidade fisiológica da semente é fator fundamental para determinar sua viabilidade e vigor. A viabilidade é determinada pelo teste de germinação e demarca-se a máxima germinação da semente sob condições controladas de ambiente ideal para a cultura. Enquanto o vigor compreende um conjunto de características que preconizam o potencial fisiológico das sementes, quando submetidas a condições adversas de ambiente e manejo durante as etapas iniciais de desenvolvimento da planta (POPINIGIS, 1977).

O principal desafio dos testes de vigor está em identificar o potencial genético associado às características de estabelecimento da plântula viável, assim como na indicação de quais genótipos são mais sensíveis ou tolerantes a condições adversas de ambiente, testando estes genótipos em laboratório quanto ao seu potencial de viabilidade associada às características de vigor. Dentre os métodos para a avaliação do vigor das sementes, destacam-se o teste de condutividade elétrica, teste do frio e envelhecimento acelerado, e índice de velocidade de germinação.

Devido à escassez de informações sobre a qualidade fisiológica das sementes de variedade de sequeiro em Santa Catarina, objetivouse, neste trabalho, resgatar os genótipos crioulos de arroz e caracterizar a qualidade fisiológica das sementes produzidas, indicando as cultivares mais promissoras.

\section{Material e métodos}

As sementes avaliadas foram colhidas de experimentos realizados na Estação Experimental da Epagri, localizada no município de Campos Novos do Estado de Santa Catarina, na safra de 2010/2011, todas nas mesmas condições experimentais, no total de onze cultivares de arroz: Amarelão, Agulha, Rosa 15, Mato Grosso, Gomes, Preto, Argentino, Kinsel, Camilo, Piriquitinho e Casca Roxa.

O município de Campos Novos está localizado à latitude $27^{\circ} 24^{\prime \prime S}$ e longitude $51^{\circ} 12^{\prime \prime} \mathrm{W}$, em altitude média de 964 metros. A temperatura média anual local é de $16,5^{\circ} \mathrm{C}$, umidade relativa do ar (UR) e precipitação média anual em torno de $76,3 \%$ e $1.853,9 \mathrm{~mm}$, respectivamente. Devido à distribuição irregular das chuvas no município, sempre que necessário, foi utilizada irrigação complementar. O fornecimento de água foi realizado através de um sistema fixo de irrigação convencional por aspersão, com precipitação de $8,0 \mathrm{~mm} \mathrm{~h}^{-1}$, fornecendo uma lâmina de água de $16 \mathrm{~mm}$. O solo utilizado foi um Nitossolo Vermelho com as seguintes características químicas $(0-20 \mathrm{~cm})$ : $\mathrm{pH}\left(\mathrm{H}_{2} \mathrm{O}\right)$ : 5,8; M.O.: 4,1\%; P: 11,6 mg dm ${ }^{-3}$ (Mehlich). A adubação foi realizada conforme 0 exigido para a cultura. $O$ delineamento experimental foi 0 de blocos ao acaso, com quatro repetições. As parcelas foram constituídas por quatro fileiras de $5 \mathrm{~m}$ de comprimento, espaçadas em 0,5 m entre si, e a área útil, composta pelas duas fileiras centrais, com 
$10 \mathrm{~m}^{2}$. A semeadura foi efetuada manualmente com 100 sementes $\mathrm{m}^{-2}$. Não foi verificada a ocorrência de danos causados por insetos e doenças, dispensando os tratamentos para os mesmos.

A colheita foi realizada quando as amostras atingiram $13 \%$ de umidade (b. u.), de forma manual, assim como o beneficiamento. Após a colheita de cada experimento, as amostras foram secas em estufa de circulação de ar até $12 \%$ de umidade (b. u.) e armazenadas em câmera seca com temperatura de $8^{\circ} \mathrm{C}$ e UR de $45 \%$ para manter a qualidade fisiológica das sementes até - momento das análises laboratoriais. Das amostras obtidas do experimento a campo, foi retirada uma amostra média, no laboratório, utilizando-se do homogeneizador tipo Gamet para obter a amostra de trabalho, com 4 repetições. As sementes foram analisadas no Laboratório de Sementes da Universidade Federal de Santa Catarina - UFSC, visando a caracterizar a qualidade fisiológica das sementes.

Antes de iniciar as análises laboratoriais do potencial fisiológico das sementes de arroz, foi efetivado em cada cultivar o teste de pureza física, o qual consiste em averiguar se a espécie em pesquisa é predominante na amostra. Em um segundo momento, foi determinado o grau de umidade da semente, utilizando duas repetições de 100 sementes mantidas em estufa a $105 \pm 3^{\circ} \mathrm{C}$ por $24 \mathrm{~h}$, de acordo com as Regras para Análise de Sementes (BRASIL, 2009). Foi constatada uma pureza de 85 a $98 \%$ e umidade de $10 \%$, mostrando-se dentro do padrão da espécie. avaliados:

Para cada cultivar de arroz, foram

Germinação: utilizou-se de quatro repetições de 50 sementes, semeadas em rolos de papel Germitest, umedecidos com volume de água destilada equivalente a três vezes a massa do papel seco, e mantidos em câmara de germinação com temperatura constante de $25^{\circ} \mathrm{C}$. No quinto dia após a semeadura, realizou-se a primeira contagem e, no oitavo dia, a contagem final de plântulas, determinando-se, assim, a porcentagem de plântulas normais (BRASIL, 2009);

Índice de Velocidade de Germinação (IVG): determinado em conjunto com o teste de germinação, avaliando-se diariamente a porcentagem de plântulas normais até os oito dias após a semeadura. O IVG foi determinado empregandose a fórmula apresentada por VIEIRA \& CARVALHO (1994): IVG $=N_{1} / D_{1}+N_{2} / D_{2}+$ $+N_{n} / D_{n}$, onde: $N_{1}, N_{2}, N_{n}=$ número de plântulas germinadas a 1; 2 e $\mathrm{n}$ dias após a montagem do teste; $D_{1}, D_{2}, D_{n}=$ número de dias após a instalação do teste;

Teste do frio: quatro repetições de 50 sementes foram semeadas em rolos de papel Germitest, umedecidos com volume de água destilada equivalente a três vezes a massa do papel seco e foram colocadas no interior de sacos de plástico e incubadas sob temperatura constante de $10 \stackrel{\circ}{ } \mathrm{C}$, por um período de cinco dias. Transcorrido esse período, as amostras foram colocadas sob temperatura constante de $25^{\circ} \mathrm{C}$, sendo a avaliação realizada no oitavo dia, contabilizando, assim, as plântulas normais, seguindo os mesmos padrões do teste de germinação (KRZYZANOWSKI et al., 1999);

Condutividade Elétrica (CE): usaram-se quatro repetições de 50 sementes, para as quais foram determinadas as massas em balança com precisão $0,01 \mathrm{~g}$ (KRZYZANOWSKI et al., 1991), colocadas em copos de plástico $(200 \mathrm{~mL})$ com $75 \mathrm{~mL}$ de água destilada, mantidos em câmara de germinação a $25^{\circ} \mathrm{C}$. Realizou-se leitura de $\mathrm{CE}$ nos períodos de imersão $(0 ; 2 ; 4 ; 6 ; 8$ e $24 \mathrm{~h})$, sendo que, em cada período, determinou-se a condutividade da solução por meio de leituras em condutivímetro Digimed, convertendo os resultados da leitura de $\mathrm{CE}$, os quais são expressos em $\mu \mathrm{S} \mathrm{cm}^{-1} \mathrm{~g}^{-1}$ de semente. A taxa de $\mathrm{CE}$ foi obtida da seguinte maneira: $\mathrm{TaxaCE}_{0-2 \mathrm{~h}}=(\mathrm{CE} \mathrm{t} 2-\mathrm{CE}$ t0) / (t2 - t0); em que $\mathrm{CE}$ t2 = CE obtida no tempo de $2 \mathrm{~h}$ de embebição e CE t0 = CE da água destilada; assim, a TaxaCE ${ }_{2-4 h}=(C E \mathrm{t} 4-\mathrm{CE}$ t2) / (t4 - t2); sendo repetidos e substituídos os valores para os demais tempos, respectivamente: TaxaCE ${ }_{4-6 h ;}$ TaxaCE ${ }_{6-8 h}$ e TaxaCE ${ }_{8-24 h}$; resultando desta maneira nas respectivas taxas de efluxo de eletrólitos (Taxas de CE) expressos em $\mu \mathrm{cm}^{-1} \mathrm{~g}^{-1} \mathrm{~h}^{-1}$;

Envelhecimento Acelerado: conduzido em caixas de plástico tipo "gerbox" modificadas, contendo $40 \mathrm{~mL}$ de água destilada, com quatro repetições de 50 sementes, de cada cultivar. Essas caixas foram mantidas a $42^{\circ} \mathrm{C}$ por um período de $72 \mathrm{~h}$ (VIEIRA \& CARVALHO, 1994). Em seguida, as sementes foram submetidas ao teste de germinação, conforme descrição anterior, com contagens das plântulas normais no $5^{\circ}$ e $8^{\circ}$ dias após o início do teste.

O delineamento experimental em laboratório foi o completamente casualizado. As comparações entre as médias foram efetuadas através do teste de Scott-Knott, a $5 \%$ de significância.

\section{Resultados e discussão}

Os resultados demonstraram a existência de variabilidade entre os genótipos estudados, considerando que todos foram produzidos na mesma safra, ambiente e condições de manejo. $\mathrm{Na}$ primeira contagem da germinação das sementes exibidas na Tabela 1 (G1), as cultivares 
Agulha e Rosa 15 apresentaram maior desempenho. Contudo, ao final do teste, na contagem final (G2), as cultivares Argentino, Kinsel, Camilo e Piriquitinho também exibiram maiores valores de germinação em relação às demais. Desta forma, observou-se claramente, na Tabela 1, que, para avaliação do percentual de germinação das sementes destas cultivares crioulas, é necessário um tempo de 8 dias. Considerando-se esse tempo, observou-se que seis cultivares (Agulha, Rosa 15, Argentino, Kinsel, Camilo e Piriquinho) demonstraram percentual germinativo próximo a
$80 \%$, o que pode ser considerado como boa característica de qualidade fisiológica nestes genótipos crioulos, considerando que os padrões mínimos de germinação para cultivares comerciais deve ser de $80 \%$ (BRASIL, 2005). O índice de velocidade de germinação (Tabela 2) evidenciou que, das seis cultivares citadas anteriormente, apenas a Argentino não apresentou vigor equivalente a sua germinação, mostrando que esta teria uma germinação mais tardia que as outras cinco, que se sobressairam no teste de germinação.

Tabela 1 - Médias dos valores de primeira contagem (G1), contagem final do teste de germinação (G2), primeira contagem após o envelhecimento acelerado (G1-EA) e contagem final de envelhecimento acelerado (G2-EA) de sementes de 11 cultivares de arroz da safra de 2010/2011. Results of the first count test (G1), final count of the germination (G2), first count after the accelerated aging (G1-EA), and the final count of accelerated aging (G2-EA) tests of seeds of eleven rice cultivars.

\begin{tabular}{lcccc}
\hline Cultivar & G1 (\%) & G2(\%) & G1-EA (\%) & G2-EA (\%) \\
\hline Amarelão & $62,0 \mathrm{~b}$ & $71,5 \mathrm{~b}$ & $82,5 \mathrm{a}$ & $87,0 \mathrm{a}$ \\
Agulha & $79,5 \mathrm{a}$ & $80,0 \mathrm{a}$ & $73,0 \mathrm{~b}$ & $83,5 \mathrm{a}$ \\
Rosa 15 & $79,5 \mathrm{a}$ & $84,0 \mathrm{a}$ & $43,5 \mathrm{~d}$ & $52,5 \mathrm{~d}$ \\
Mato Grosso & $56,5 \mathrm{~b}$ & $62,5 \mathrm{~b}$ & $72,5 \mathrm{~b}$ & $75,5 \mathrm{~b}$ \\
Gomes & $54,5 \mathrm{~b}$ & $64,5 \mathrm{~b}$ & $62,0 \mathrm{c}$ & $66,0 \mathrm{c}$ \\
Preto & $55,0 \mathrm{~b}$ & $62,0 \mathrm{~b}$ & $51,5 \mathrm{~d}$ & $66,5 \mathrm{c}$ \\
Argentino & $50,0 \mathrm{c}$ & $75,0 \mathrm{a}$ & $61,0 \mathrm{c}$ & $76,5 \mathrm{~b}$ \\
Kinsel & $48,0 \mathrm{c}$ & $76,5 \mathrm{a}$ & $66,5 \mathrm{c}$ & $78,0 \mathrm{~b}$ \\
Camilo & $57,5 \mathrm{~b}$ & $83,5 \mathrm{a}$ & $88,0 \mathrm{a}$ & $88,5 \mathrm{a}$ \\
Piriquitinho & $45,5 \mathrm{c}$ & $81,0 \mathrm{a}$ & $85,5 \mathrm{a}$ & $85,5 \mathrm{a}$ \\
Casca Roxa & $49,5 \mathrm{c}$ & $70,5 \mathrm{~b}$ & $67,5 \mathrm{c}$ & $64,0 \mathrm{c}$ \\
\hline F & 13,6 & 6,3 & 18,2 & 14,3 \\
\hline CV\% & 10,9 & 8,8 & 9,5 & 7,8 \\
\hline
\end{tabular}

Médias seguidas por diferentes letras na coluna diferem entre si, pelo teste de Scott-Knott, a 5\% de significancia.

Quanto ao vigor pelo teste de envelhecimento acelerado, verificou-se, na Tabela 1, que das onze cultivares, quatro retrataram alto desempenho quando submetidas a uma situação de estresse (Amarelão, Agulha, Camilo e Piriquitinho) por alta temperatura e umidade, as quais são mais promissoras para condições de estresse desta natureza a campo, e também com potencial de armazenamento por tempos mais prolongados. Percebe-se que a cultivar Amarelão aumentou seu vigor ao estar em situação de estresse, enquanto a cultivar Rosa 15, que havia exposto alto potencial no teste de germinação, ao ser submetida em condições de estresses, teve queda drástica em seu desempenho. A resposta diferenciada dos genótipos às condições de estresse, pelo teste de envelhecimento acelerado, permitiu constatar diferenças no vigor das sementes em função da cultivar avaliada (Tabela 1). O efeito do genótipo sobre as caracteristicas de vigor em sementes já foi constatado previamente por outros autores com sementes de arroz (BALDIGA et al., 2007).

Com relação às alterações fisiológicas ocorridas em consequência do frio, pôde-se averiguar que o estresse ocasionado pelas baixas temperaturas foi eficiente em indicar os genótipos mais tolerantes ao frio. A cultivar Camilo apresentou maior tolerância ao frio, mantendo seu vigor em $83 \%$ (Tabela 2). As outras cultivares, com exceção de Amarelão, Preto e Casca Roxa, apresentaram resultados semelhantes, sendo estes os menos indicados para cultivo em regiões com ocorrência de baixas temperaturas durante a fase de germinação. A utilização deste teste é importante para a avaliação da qualidade fisiológica nas cultivares que serão utilizadas em regiões de baixas temperaturas, como a região Sul, pois no estádio de germinação, os sintomas de danos pelo frio, mais comumente observados, são o atraso e a diminuição na porcentagem de germinação. Durante o estádio de plântula, o frio pode provocar atraso no desenvolvimento, redução na estatura e amarelecimento das folhas. No período reprodutivo, os sintomas de dano pelo frio são má inserção da panícula, esterilidade e manchas nas espiguetas (SOUZA, 1990). CRUZ \& MILACH (2000), em um estudo de capacidade 
combinatória de seis genótipos de arroz, concluíram que a porcentagem de germinação e a redução do comprimento do coleóptilo sob temperatura baixa são herdáveis, e tanto as ações gênicas aditivas quanto de dominância e epistasia são importantes na determinação da herança desses caracteres.

O vigor, com base nas leituras de condutividade elétrica (CE), foi também diferenciado entre os genótipos, com relação ao período de imersão de sementes, para as onze cultivares. Verificou-se, para todas as cultivares, aumento progressivo da CE com o aumento do número de horas, corroborando os dados de DIAS \& MARCOS FILHO (1996). No entanto, a taxa de CE foi gradativamente diminuindo (Figura 1). Tal redução significa que a quantidade de eletrólitos liberados pelas sementes na solução de imersão foi decrescendo, evidenciando a estabilização na organização das membranas.

Tabela 2 - Médias dos valores de Índice de Velocidade de Germinação (IVG), condutividade elétrica (CE) e contagem final de teste do frio (TF) de sementes de 11 cultivares de arroz da safra de 2010/2011. Results of the germination speed index (IVG), electrical conductivity (CE), final count of the cold test (TF) of seeds of eleven rice cultivars.

\begin{tabular}{llcc}
\hline \multicolumn{1}{c}{ Cultivar } & IVG & TF $(\%)$ & $\mathrm{CE}\left(\mu \mathrm{S} \mathrm{cm}^{-1} \mathrm{~g}^{-1}\right)$ \\
\hline Amarelão & $6,5 \mathrm{~b}$ & $62,5 \mathrm{~b}$ & $41,7 \mathrm{~b}$ \\
Agulha & $7,2 \mathrm{a}$ & $69,5 \mathrm{a}$ & $24,8 \mathrm{c}$ \\
Rosa 15 & $7,3 \mathrm{a}$ & $73,0 \mathrm{a}$ & $23,9 \mathrm{c}$ \\
Mato Grosso & $6,3 \mathrm{~b}$ & $70,5 \mathrm{a}$ & $27,5 \mathrm{c}$ \\
Gomes & $6,8 \mathrm{~b}$ & $75,0 \mathrm{a}$ & $25,0 \mathrm{c}$ \\
Preto & $6,5 \mathrm{~b}$ & $66,0 \mathrm{~b}$ & $54,5 \mathrm{a}$ \\
Argentino & $6,4 \mathrm{~b}$ & $70,0 \mathrm{a}$ & $29,9 \mathrm{c}$ \\
Kinsel & $7,2 \mathrm{a}$ & $74,5 \mathrm{a}$ & $27,6 \mathrm{c}$ \\
Camilo & $7,1 \mathrm{a}$ & $83,0 \mathrm{a}$ & $37,8 \mathrm{~b}$ \\
Piriquitinho & $7,6 \mathrm{a}$ & $77,0 \mathrm{a}$ & $23,8 \mathrm{c}$ \\
Casca Roxa & $6,3 \mathrm{~b}$ & $57,5 \mathrm{~b}$ & $52,7 \mathrm{a}$ \\
\hline F & 6,6 & 5,8 & 38,1 \\
\hline CV\% & 5,2 & 8,3 & 11,1
\end{tabular}

Médias seguidas por diferentes letras na coluna diferem entre si, pelo teste de Scott-Knott, a 5\% de probabilidade.

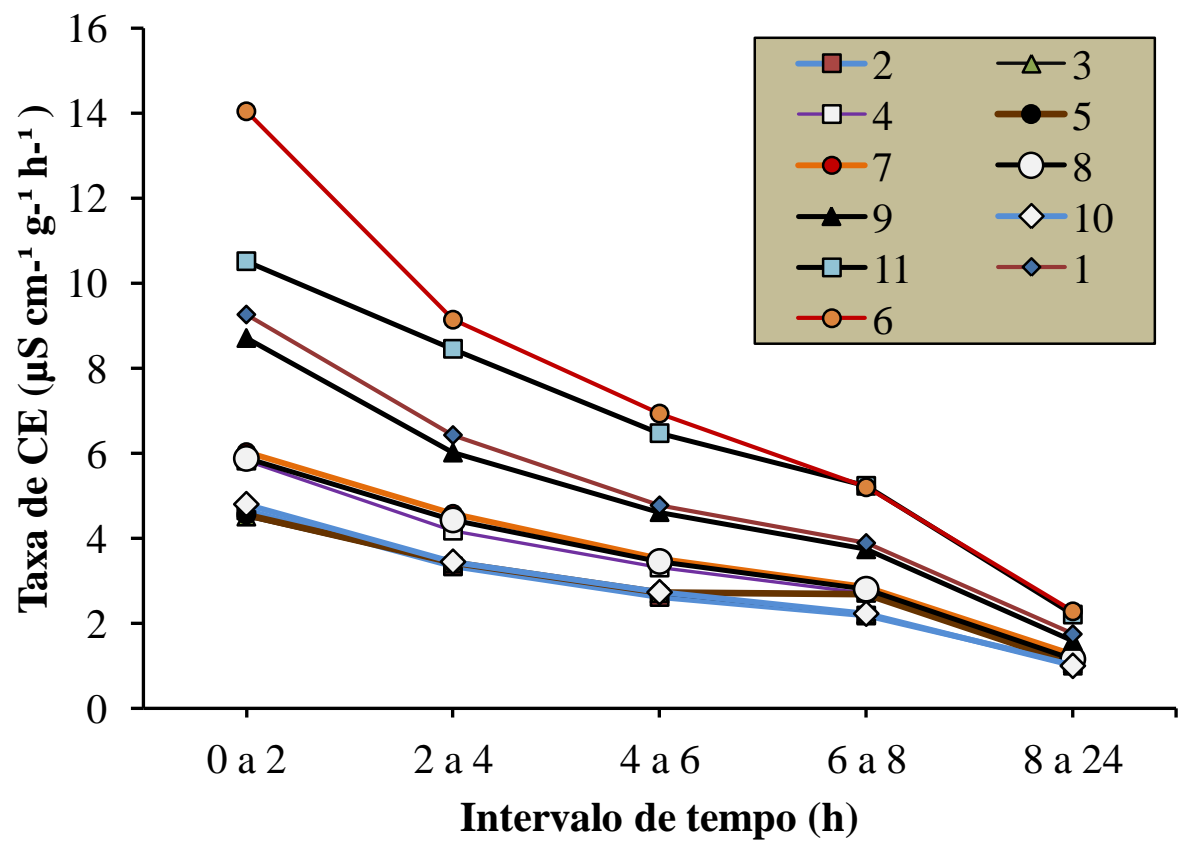

Figura 1 - Taxa de condutividade eletrica (CE) de 11 cultivares de arroz (1 - Amarelão; 2 - Agulha; 3 - Rosa 15; 4 - Mato Grosso; 5 - Gomes; 6 - Preto; 7 - Argentino; 8 - Kinsel; 9 - Camilo; 10 - Piriquitinho; 11 - Casca Roxa) da safra de 2010/2011, no decorrer dos períodos de imersão (0-2, 2-4, 4-6, 6-8 e 8-24 h). Results of the electrical conductivity (CE) of seeds of eleven rice cultivars. 
As reduções verificadas foram mais acentuadas nas cultivares Preto e Casca Roxa, porque apresentavam valores médios de CE mais elevados desde o início da embebição (Tabela 2), formando um grupo com maior taxa de vazamento de solutos seguidas pelas cultivares Amarelão e Camilo, indicando que estas cultivares (Preto, Casca Roxa, Amarelão e Camilo) apresentam menor vigor de suas sementes, pelo teste de CE, e, depois, o terceiro grupo, pelas demais cultivares (Figura 1) como as de sementes com maior vigor.

De acordo com MARCOS FILHO (2005), as sementes mais deterioradas apresentam menor velocidade de restabelecimento da integridade das membranas durante a imersão e, consequentemente, liberam maiores quantidades de solutos para a solução. Entretanto, os resultados apresentados na Figura 1 evidenciam que 0 tempo de estabilização estabelecido entre todos os genótipos avaliados de 8 horas, em que se constatou que a taxa de vazamento de solutos já era suficientemente baixa, não necessitando da espera de 24 horas, conforme preconizado na maioria dos trabalhos científicos, para a cultura do arroz (SOUZA et al., 2005; NEVES et al., 2010).

Conforme se observa na Tabela 2, as cultivares Preto e Casca Roxa demonstraram maior valor de condutividade, ou seja, maior valor de deterioração, o que ocasiona menor qualidade das sementes. Isso justifica o fraco desempenho destas cultivares nos outros testes, pois a alta deterioração provoca perda de vigor da semente, o que acarreta baixa tolerância ao estresse e menor velocidade de germinação.

Ao relacionar o teste de condutividade com outros testes de vigor utilizados, foi possível detectar as pequenas diferenças existentes entre os genótipos avaliados. Todas as cinco cultivares que apresentaram destaque quanto ao vigor pelo IVG, também demonstraram bom desempenho na tolerância ao frio e baixos valores de condutividade elétrica, destacando--se sempre a cultivar Camilo como a de sementes mais vigorosas.

\section{Conclusões}

A qualidade fisiológica das sementes foi dependente do genótipo, o que permitiu indicar os genótipos Agulha, Rosa 15 e Camilo como os mais promissores para as características de viablidade e vigor.

\section{Agradecimento}

Os autores agradecem ao CNPq, pela concessão de bolsa para o primeiro autor, durante o desenvolvimento do projeto de pesquisa na Universidade Federal de Santa Catarina, e o apoio financeiro concedido pelo CNPq, edital 58/2010, parceria com MDA.

\section{Referências}

BALDIGA, R. F.; ALMEIDA, A.; LAUXEN, L. R.; PINHO, M. S.; DUARTE, V. B. Utilização de testes de vigor para avaliação da qualidade fisiológica de sementes de três cultivares de arroz (Oryza sativa L.). In: CONGRESSO DE INICIAÇÃO CIENTÍFICA, 16., 2007, Pelotas. p.15. Disponível em: <http://www2.ufpel.edu.br/cic/ 2007/cd/pdf/CA/CA_01644.pdf>. Acesso em: 28 abr. 2014.

BRASIL. Ministério da Agricultura, Pecuária e Abastecimento. Regras para análise de sementes. Brasília: SNDA/DNDV/CLAV, 2009. 365p.

BRASIL. Ministério da Agricultura, Pecuária e Abastecimento. Instrução Normativa 25/2005, de 16 de dezembro de 2005. (Anexo II - Padrões para produção e comercialização de sementes de arroz). Brasília, DF: SNAD/DNDN/CLAV. Diário Oficial da União, Brasília, DF, 20 dez. 2005, p.18, Seção 1.

CEPA - Centro de Socioeconomia e Planejamento Agrícola: Arroz - Panorama da cultura nas últimas safras. 2009. Disponível em: <http://cepa.epagri.sc.gov.br/Informativos agropecuarios/arroz/arroz_31.07.09.htm >Acesso em: 11 jul. 2012.

CRUZ, C. P.; MILACH, S. C. K. Melhoramento genético para tolerância ao frio em arroz irrigado. Ciência Rural, Santa Maria, v.30, n.5, p.909-917, 2000.

DIAS, D. C. F. S.; MARCOS FILHO, J. Testes de condutividade elétrica para avaliação do vigor de sementes de soja (Glycine max (L.) Merril). Scientia Agrícola, Piracicaba, v.53, n.1, p1-11, 1996.

KRYZANOWSKI, F. C.; FRANÇA NETO, J. B.; HENNING, A. A. Relato dos testes de vigor disponíveis para as grandes culturas. Informativo ABRATES, Londrina, v.1, n.2, p.15-53, 1991.

KRZYZANOWSKI, F. C.; VIEIRA, R. D., FRANÇA NETO, J. B. Vigor de sementes e testes. Londrina: ABRATES, 1999. 218p.

MARCOS FILHO, J. Fisiologia de sementes de plantas cultivadas. Piracicaba: Fealq, 2005. 495p.

NEVES, L. A. S.; BASTOS, C; GOULART, E. P.; HOFFMANN, C. E. F. Qualidade fisiológica de sementes de arroz irrigado submetidas a ácidos orgânicos. Revista de Ciências Agroveterinárias. Lages, v.9, n.2, p.169-177, 2010.

POPINIGIS, F. Fisiologia da semente. Brasília: AGIPLAN, 1977. 289p. 
RIBEIRO, N.; ANTUNES, I. F.; POERSCHLL, N. L.; ROSA, S. S.; TEIXEIRA, M. G.; GOMES, A. L. $S$. Potencial de uso agrícola e nutricional de cultivares crioulas de feijão. Ciência Rural, Santa Maria, v.38, n.3, p.628-634, 2008.

SILVA, O. F. Socioeconomia para Arroz e Feijão, 2010. Disponível em: <http://www.cnpaf.embrapa.br>. Acesso em: 27 jul. 2012.

SOUZA, L. C. D.; CARVALHO, M. A. C.; BRAGA, L. F.; SOUSA, M. P. Qualidade fisiológica de sementes de arroz da região de Matupá-MT. Revista de Ciências Agro-Ambientais, Alta Floresta, v.3, n.1, p.110-116, 2005.
SOUZA, P. R. Alguns aspectos da influência do clima temperado sobre a cultura do arroz irrigado, no sul do Brasil. Lavoura Arrozeira, Porto Alegre, v.43, n.389, p.9-11, 1990.

VIEIRA, R. D.; CARVALHO, N. M. Testes de vigor em sementes. Jaboticabal: Funep, 1994. $164 p$. 